\title{
Natronorubrum sulfidifaciens sp. nov., an extremely haloalkaliphilic archaeon isolated from Aiding salt lake in Xin-Jiang, China
}

Correspondence

Pei-Jin Zhou

zhou@sun.im.ac.cn
Heng-Lin Cui, ${ }^{1,2,3}$ Dilbr Tohty, ${ }^{4}$ Hong-Can Liu, ${ }^{1}$ Shuang-Jiang Liu, ${ }^{1}$ Aharon Oren ${ }^{5}$ and Pei-Jin Zhou ${ }^{1}$

\author{
'State Key Laboratory of Microbial Resources, Institute of Microbiology, Chinese Academy of \\ Sciences, Beijing 100080, People's Republic of China \\ ${ }^{2}$ Graduate University of Chinese Academy of Sciences, Beijing 100049, People's Republic of \\ China \\ ${ }^{3}$ School of Food \& Biological Engineering, Jiangsu University, Zhenjiang 212013, People's \\ Republic of China \\ ${ }^{4}$ College of Life Sciences, Xin-Jiang Normal University, Urumqi 830053, People's Republic of \\ China \\ ${ }^{5}$ Institute of Life Sciences and the Moshe Shilo Minerva Center for Marine Biogeochemistry, \\ The Hebrew University of Jerusalem, Jerusalem 91904, Israel
}

\begin{abstract}
An extremely haloalkaliphilic archaeon, strain $\mathrm{AD}^{\top}{ }^{\top}$, was isolated from Aiding salt lake in Xin-Jiang, China. Strain $A D 2^{\top}$ required at least $12 \% \mathrm{NaCl}$ for growth. $\mathrm{MgCl}_{2}$ was not required. The isolate was able to grow over a $\mathrm{pH}$ range of 8.0-10.0 and temperature range of $20-55^{\circ} \mathrm{C}$, with optimal growth at $\mathrm{pH} 8.7-9.2$ and $44-47^{\circ} \mathrm{C}$. The major polar lipids of strain $A D 2^{\top}$ were phosphatidylglycerol and phosphatidylglycerol phosphate methyl ester; glycolipids were not detected. Analysis of its $16 \mathrm{~S}$ rRNA gene sequence indicated that strain $\operatorname{AD}^{\top}{ }^{\top}$ was phylogenetically related to members of the genus Natronorubrum, with sequence similarities to the type strains of Natronorubrum bangense, Natronorubrum tibetense and Natronorubrum aibiense of 97.1, 95.9 and $96.1 \%$, respectively. The $\mathrm{G}+\mathrm{C}$ content of its DNA was $60.9 \mathrm{~mol} \%\left(T_{\mathrm{m}}\right)$. Levels of DNA-DNA relatedness between strain $\mathrm{AD}^{\top}$ and the type strains of Nrr. bangense, Nrr. tibetense and $N$ rr. aibiense were 49,38 and $41 \%$, respectively. It was concluded that strain $A D 2^{\top}$ represents a novel species of the genus Natronorubrum, for which the name Natronorubrum sulfidifaciens sp. nov. is proposed. The type strain is $\mathrm{AD}^{\top}\left(=\mathrm{CGMCC} 1.6307^{\top}=\mathrm{JCM} 14089^{\top}\right)$.
\end{abstract}

The genus Natronorubrum was established by $\mathrm{Xu}$ et al. (1999) to accommodate two novel haloalkaliphilic archaeal species, Natronorubrum bangense and Natronorubrum tibetense, which were isolated from the Bange soda lake in Tibet, China. Recently, Natronorubrum aibiense was added to the genus (Cui et al., 2006a). Members of the genus Natronorubrum have been frequently isolated from several salt lakes in China (Fan et al., 2003; Pan et al., 2006). The Aiding salt lake $\left(42^{\circ} 32^{\prime} 10^{\prime \prime}-42^{\circ} 49^{\prime} 13^{\prime \prime} \mathrm{N} 89^{\circ} 10^{\prime} 32^{\prime \prime}-89^{\circ}\right.$ $54^{\prime} 32^{\prime \prime} \mathrm{E}$ ), the lowest point in China (155 m below sea-level) and after the Dead Sea the second lowest inland depression in the world, has been a target for the study of halophilic archaeal diversity under extremely high salt conditions for

The GenBank/EMBL/DDBJ accession number for the $16 \mathrm{~S}$ rRNA gene sequence of strain $\mathrm{AD}^{\top}{ }^{\top}$ is DO535889.

A two-dimensional thin-layer chromatogram of the phospholipids from strain $A D 2^{\top}$ is available as supplementary material in IJSEM Online. many years (Tohty \& Xu, 2001; Cui et al., 2006b). Here we describe a haloalkaliphilic strain isolated from Aiding salt lake, which we propose to classify as representing a novel species of the genus Natronorubrum.

Strain $\mathrm{AD} 2^{\mathrm{T}}$ was isolated from sediment of the Aiding salt lake. The medium and method used for isolation were as described by Xu et al. (1999, 2001). The strain was routinely grown aerobically at $45^{\circ} \mathrm{C}$ in a complex medium containing the following ingredients (per litre distilled water): $7.5 \mathrm{~g}$ Casamino acids (Difco), $10 \mathrm{~g}$ yeast extract (Difco), $3.0 \mathrm{~g}$ trisodium citrate, $0.1 \mathrm{~g} \mathrm{MgSO}_{4} .7 \mathrm{H}_{2} \mathrm{O}, 2.0 \mathrm{~g} \mathrm{KCl}, 0.036 \mathrm{~g}$ $\mathrm{FeCl}_{2} .7 \mathrm{H}_{2} \mathrm{O}, 180 \mathrm{~g} \mathrm{NaCl}$ and $10 \mathrm{~g} \mathrm{Na}_{2} \mathrm{CO}_{3}$.

Phenotypic tests were performed according to the proposed minimal standards for the description of novel taxa in the order Halobacteriales (Oren et al., 1997). Colony morphology was observed on salt-milk agar medium (Kocur \& Hodgkiss, 1973), the final $\mathrm{pH}$ of which was adjusted to 
9.0-9.5 with $1 \mathrm{M} \mathrm{NaOH}$, after incubation at $45^{\circ} \mathrm{C}$ for 7-10 days. The production of $\mathrm{H}_{2} \mathrm{~S}$ was tested by growing the isolate in a tube with the above-described liquid complex medium supplemented with $0.5 \% \mathrm{Na}_{2} \mathrm{~S}_{2} \mathrm{O}_{3}$; a filter paper strip impregnated with lead acetate was used for detection of $\mathrm{H}_{2} \mathrm{~S}$. Cell morphology and growth characteristic tests, miscellaneous biochemical tests, nutrition tests, sensitivity to antimicrobial agents and polar lipid analysis were performed as described and cited by Xu et al. (1999, 2001). Nucleic acid characterization was performed as described and cited by Feng et al. (2005) and the DNA G + C content was determined by the thermal denaturation method (Marmur \& Doty, 1962).

Cells of strain $\mathrm{AD} 2^{\mathrm{T}}$ were motile, pleomorphic (rods, triangular or disc-shaped), Gram-negative and were able to grow over a wide range of salinities $(12-28 \% \mathrm{NaCl}$; optimal growth at $18 \%$ ). Colonies on salt-milk agar medium were red-pigmented. Detailed results of phenotypic tests and nutritional features of strain $\mathrm{AD}^{\mathrm{T}}$ are given in the species description below and some differential properties in comparison with recognized members of the genus Natronorubrum are listed in Table 1.

Polar lipid analysis indicated that strain $\mathrm{AD} 2{ }^{\mathrm{T}}$ contained phosphatidylglycerol and phosphatidylglycerol phosphate methyl ester (Kates, 1986; see Supplementary Fig. S1 available in IJSEM Online), which are the major phospholipids found in members of the genus Natronorubrum. No glycolipids were detected (Supplementary Fig. S1).

The DNA G + C content of strain $\mathrm{AD} 2^{\mathrm{T}}$ was $60.9 \mathrm{~mol} \%$. Phylogenetic analysis based on the 16S rRNA gene according to the neighbour-joining method (Kumar et al., 2004)

Table 1. Differential characteristics between strain $A D 2^{\top}$ and other members of the genus Natronorubrum

Taxa: 1, strain $\mathrm{AD} 2^{\mathrm{T}} ; 2$, Nrr. bangense $\mathrm{A} 33^{\mathrm{T}} ; 3$, Nrr. tibetense GA $33^{\mathrm{T}} ; 4$, Nrr. aibiense $7-3^{\mathrm{T}}$.

\begin{tabular}{|lcccc|}
\hline Characteristic & $\mathbf{1}$ & $\mathbf{2}$ & $\mathbf{3}$ & $\mathbf{4}$ \\
\hline Optimum pH & $8.7-9.2$ & 9.5 & 9.0 & $7.5-8.0$ \\
$\mathrm{H}_{2} \mathrm{~S}$ formation & + & - & - & - \\
Hydrolysis of Tweens 40, & - & - & + & - \\
$\quad 60$ and 80 & & & & \\
Gelatin liquefaction & - & - & + & - \\
Sensitivity to antibiotics: & & & & \\
$\quad$ Erythromycin & + & + & + & - \\
$\quad$ Ciprofloxacin & + & - & - & - \\
$\quad$ Tetracycline & + & + & + & - \\
Utilization of: & & & & \\
$\quad$ Galactose & - & - & - & + \\
$\quad$ Succinate & + & + & + & - \\
DNA G + C content (mol\%) & 60.9 & 59.9 & 60.1 & 61.2 \\
Presence of glycolipids & - & - & - & + \\
\hline
\end{tabular}

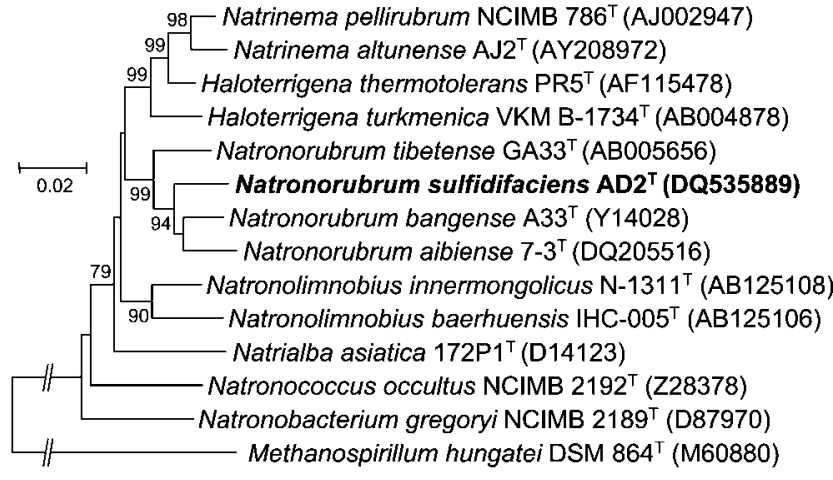

Fig. 1. Phylogenetic tree based on 16S rRNA gene sequences showing the relationship between strain $\mathrm{AD}^{\top}$, recognized members of the genus Natronorubrum and related genera within the family Halobacteriaceae. Bootstrap values (\%) are based on 1000 replicates and are shown for branches with more than $70 \%$ support. Bar, 0.02 expected changes per site.

indicated that strain $\mathrm{AD}^{\mathrm{T}}$ was closely related to $N r$. bangense, Nrr. tibetense and Nrr. aibiense (Fig. 1), with $16 \mathrm{~S}$ rRNA gene sequence similarities to the type strains of these species of 97.1, 95.9 and $96.1 \%$, respectively. Levels of DNA-DNA relatedness between strain $\mathrm{AD}^{\mathrm{T}}$ and the type strains of Nrr. bangense, Nrr. tibetense and Nrr. aibiense were 49,38 and $41 \%$, respectively.

Based on these results, it is concluded that strain $\mathrm{AD} 2^{\mathrm{T}}$ represents a novel species of the genus Natronorubrum, for which the name Natronorubrum sulfidifaciens sp. nov is proposed.

\section{Description of Natronorubrum sulfidifaciens sp. nov.}

Natronorubrum sulfidifaciens (sul.fi.di.fa'ci.ens. N.L. n. sulfidum sulfide; L. part. faciens making, producing; N.L. part. adj. sulfidifaciens sulfide-producing).

Cells are motile, pleomorphic (rods, triangular or discshaped) and Gram-negative. Colonies on agar plates containing $3.1 \mathrm{M} \mathrm{NaCl}$ are red, elevated and round. Chemoorganotrophic and aerobic. Growth occurs at $\mathrm{NaCl}$ concentrations of $2.1-4.8 \mathrm{M}$, at an $\mathrm{Mg}^{2+}$ concentration of $0.1 \mathrm{M}$, at $\mathrm{pH} 8.0-10.0$ and at $20-55^{\circ} \mathrm{C}$. The optimal $\mathrm{NaCl}$ concentration, $\mathrm{pH}$ and temperature for growth are $3.1 \mathrm{M}$, pH 8.7-9.2 and $44-47^{\circ} \mathrm{C}$. Catalase- and oxidase-positive. Anaerobic growth with nitrate, arginine and DMSO does not occur. Nitrate reduction to nitrite is observed. $\mathrm{H}_{2} \mathrm{~S}$ is produced from $\mathrm{Na}_{2} \mathrm{~S}_{2} \mathrm{O}_{3}$. Positive for indole formation. Tweens 20, 40, 60 and 80 are not hydrolysed. Negative for caseinase, amylase and gelatinase. The following substrates are utilized as carbon sources: glucose, sucrose, maltose, glycerol, lactate, malate, succinate, acetate, pyruvate, fumarate and glutamate. Mannose, galactose, fructose, sorbose, xylose, D-ribose, lactose, starch, mannitol, sorbitol, 
citrate, glycine, L-alanine, L-arginine, L-aspartic acid, L-lysine and L-ornithine are not utilized as carbon sources. Sensitive to the following antibiotics ( $\mu \mathrm{g}$ per disc): erythromycin (15), rifampicin (5), novobiocin (30), tetracycline (30) and ciprofloxacin (5). Resistant to the following antibiotics ( $\mu$ g per disc, unless otherwise indicated): ampicillin (10), chloramphenicol (30), kanamycin (30), neomycin (30), vancomycin (30), norfloxacin (10), streptomycin (10), bacitracin (0.04 IU per disc) and penicillin G (10 IU per disc). The major polar lipids are phosphatidylglycerol and phosphatidylglycerol phosphate methyl ester. The DNA $\mathrm{G}+\mathrm{C}$ content is $60.9 \%\left(T_{\mathrm{m}}\right)$.

The type strain, AD2 ${ }^{\mathrm{T}}$ ( = CGMCC $1.6307^{\mathrm{T}}=\mathrm{JCM} 14089^{\mathrm{T}}$ ), was isolated from Aiding salt lake in Xin-Jiang, China.

\section{Acknowledgements}

This work was supported by the National Basic Research Program of China (2004CB719601) and a grant from the Chinese Academy of Sciences (KJCX1-SW-07).

\section{References}

Cui, H.-L., Tohty, D., Feng, J., Zhou, P.-J. \& Liu, S.-J. (2006a). Natronorubrum aibiense sp. nov., an extremely halophilic archaeon isolated from Aibi salt lake in Xin-Jiang, China, and emended description of the genus Natronorubrum. Int J Syst Evol Microbiol 56, 1515-1517.

Cui, H.-L., Yang, Y., Tohty, D., Zhou, P.-J. \& Liu, S.-J. (2006b). Biodiversity of halophilic archaea isolated from two salt lakes in Xin-Jiang region of China. Wei Sheng Wu Xue Bao 46, 171-176.
Fan, H.-P., Xue, Y.-F., Zeng, Y., Zhou, P.-J. \& Ma, Y.-H. (2003). Archaeal diversity of Zabuye lake in Tibet analyzed by cultureindependent approach. Wei Sheng Wu Xue Bao 43, 401-408.

Feng, J., Zhou, P.-J., Liu, S.-J. \& Warren-Rhodes, K. (2005). Halorubrum alkaliphilum sp. nov., a novel haloalkaliphile isolated from a soda lake in Xin-Jiang, China. Int J Syst Evol Microbiol 55, 149-152.

Kates, M. (1986). Techniques of Lipidology, 2nd edn. Amsterdam: Elsevier.

Kocur, M. \& Hodgkiss, W. (1973). Taxonomic status of the genus Halococcus Schoop. Int J Syst Bacteriol 23, 151-156.

Kumar, S., Tamura, K. \& Nei, M. (2004). MEGA3: integrated software for molecular evolutionary genetics analysis and sequence alignment. Brief Bioinform 5, 150-163.

Marmur, J. \& Doty, P. (1962). Determination of the base composition of deoxyribonucleic acid from its thermal denaturation temperature. J Mol Biol 4, 109-118.

Oren, A., Ventosa, A. \& Grant, W. D. (1997). Proposal of minimal standards for the description of new taxa in the order Halobacteriales. Int J Syst Bacteriol 47, 233-238.

Pan, H.-L., Zhou, C., Wang, H.-L., Xue, Y. F. \& Ma, Y.-H. (2006). Diversity of halophilic archaea in hypersaline lakes of Inner Mongolia, China. Wei Sheng Wu Xue Bao 46, 1-6.

Tohty, D. \& Xu, X.-J. (2001). The numerical distribution of halophilic bacteria and halotolerant bacteria in Aydin Lake and the surrounding area. Acta Ecol Sin 21, 1388-1391.

Xu, Y., Zhou, P.-J. \& Tian, X.-Y. (1999). Characterization of two novel haloalkaliphilic archaea Natronorubrum bangense gen. nov., sp. nov. and Natronorubrum tibetense gen. nov., sp. nov. Int J Syst Bacteriol 49, 261-266.

Xu, Y., Wang, Z.-X., Xue, Y.-F., Zhou, P.-J., Ma, Y.-H., Ventosa, A. \& Grant, W. D. (2001). Natrialba hulunbeirensis sp. nov. and Natrialba chahannaoensis sp. nov., novel haloalkaliphilic archaea from soda lakes in Inner Mongolia Autonomous Region, China. Int J Syst Evol Microbiol 51, 1693-1698. 